GRASAS Y ACEITES 69 (1)

January-March 2018, e236

ISSN-L: 0017-3495

https://doi.org/10.3989/gya.0996171

\title{
Use of Echium oil fatty acids and tricaprylin as substrates of enzymatic interesterification for the production of structured lipids
}

\author{
A. Yüksel ${ }^{\mathrm{a}}$, N. Şahin-Yeşilçubuk ${ }^{\mathrm{a}, 凶}$ \\ ${ }^{a}$ Department of Food Engineering, Faculty of Chemical and Metallurgical Engineering, Istanbul Technical University, Maslak, \\ TR-34469, Istanbul, Turkey \\ ${ }^{\otimes}$ Corresponding author: sahinnes@itu.edu.tr
}

Submitted: 02 October 2017; Accepted: 15 November 2017

SUMMARY: Structured lipids (SLs) were produced from the free fatty acids of Echium oil and tricaprylin by enzymatic acidolysis reactions. Lipozyme ${ }^{\circledR}$ RM IM, immobilized $s n-1,3$ specific lipase was used in the enzymatic reactions. In order to optimize the incorporation of stearidonic acid (SDA), three factors were chosen [Reaction temperature $\left(50-60^{\circ} \mathrm{C}\right)$, reaction time (6-12 hour) and substrate molar ratio (3-6 mol $/ \mathrm{mol}$ (total free fatty acids/ tricaprylin)] for the application of response surface methodology (RSM) using a central composite circumscribed design (CCC) with five levels. The optimum temperature, time and substrate molar ratio obtained from the models were $60{ }^{\circ} \mathrm{C} ; 6 \mathrm{~h}, 6 \mathrm{~mol} / \mathrm{mol}$, respectively. Furthermore, SLs with $6.2 \%$ SDA content at $s n-2$ position were produced by scaling up the process. SL was obtained with nearly $78-79 \%$ of long-chain fatty acids at the $s n-2$ position. According to the melting profile analysis, the melting peaks of tricaprylin and Echium oil were sharper and narrower while the SL had more broadened peaks.

KEYWORDS: Echium oil; Enzymatic acidolysis; Lipozyme ${ }^{\circledR}$ RM IM; Response surface methodology; Stearidonic acid; Tricaprylin

RESUMEN: Uso de ácidos grasos de aceite de Echium y tricaprilina como sustratos de interesterificación enzimática para la producción de lípidos estructurados. Se produjeron lípidos estructurados (SL) a partir de ácidos grasos libres de aceite de Echium y tricaprilina mediante reacciones de acidolisis enzimática. Se usó Lipozyme ${ }^{\mathbb{B}}$ RM IM, lipasa inmovilizada específica de sn-1,3 en las reacciones enzimáticas. Para optimizar la incorporación de ácido estearidónico (SDA), se eligieron tres factores [Temperatura de reacción $\left(50-60{ }^{\circ} \mathrm{C}\right)$, tiempo de reacción (6-12 horas) y proporción molar del sustrato (3-6 mol/mol (total de ácidos grasos libres) / tricaprylin)] para la aplicación de la metodología de superficie de respuesta (RSM) mediante el uso de un diseño compuesto central circunscrito (CCC) con cinco niveles. La relación óptima de temperatura, tiempo y sustrato obtenida de los modelos fue $60{ }^{\circ} \mathrm{C} ; 6 \mathrm{~h}, 6 \mathrm{~mol} / \mathrm{mol}$. Además, se produjeron SL con un contenido de SDA del 6,2\% en la posición sn-2 mediante el proceso de escalamiento, SL se obtuvo con casi $78-79 \%$ de ácidos grasos de cadena larga en la posición sn-2. Según el análisis del perfil de fusión, los picos de fusión de la tricaprilina y el aceite de Echium fueron más agudos y estrechos, mientras que los SL tuvieron picos más amplios.

PALABRAS CLAVE: Aceite de Echium; Ácido estearidónico; Acidolisis enzimática; Lipozyme ${ }^{\circledR}$ RM IM; Metodología de superficie de respuesta; Tricaprilina

ORCID ID: Yüksel A https://orcid.org/0000-0002-3795-9077, Şahin-Yeşilçubuk N https://orcid.org/0000-0002-4179-1932

Citation/Cómo citar este artículo: Yüksel A, Şahin-Yeşilçubuk N. 2108. Use of Echium oil fatty acids and tricaprylin as substrates of enzymatic interesterification for the production of structured lipids. Grasas Aceites 69 (1), e236. https:// doi.org/10.3989/gya.0996171

Copyright: (C2018 CSIC. This is an open-access article distributed under the terms of the Creative Commons Attribution 4.0 International (CC BY 4.0) License. 


\section{INTRODUCTION}

The health benefits of medium chain fatty acids (MCFAs) and long chain fatty acids (LCFAs) are well documented and today's biotechnological improvements allow for the production of SLs which include both of these fatty acids in one triacylglycerol (TAG) molecule. Recently, the production of MLM-type SLs with medium chain fatty acids (MCFAs, C6-C10) at $s n-1$ and $s n-3$ positions, and long chain saturated and unsaturated fatty acids (LCFAs, C12-C24) at $s n-2$ position has gained attention for clinical and nutritional purposes (Osborn and Akoh, 2002). During digestion, MCFAs are cleaved from the TAG molecule via the activity of $s n-1,3$ specific pancreatic lipase and then transported to the liver through the portal vein where it is rapidly turn into glucose. In addition, MCFAs do not have carnitine dependence and they do not need chylomicrons; they can be easily oxidized to produce energy as well. Furthermore, MCFAs do not further esterified as a newly synthesized TAG molecule; thus they have a low tendency to be deposited as body fat which is beneficial for the control of body weight (Akoh et al., 2002; Osborn and Akoh, 2002). LCFAs are absorbed as $s n-2$ monoacylglycerol (MAG) through lymphatic system and are mainly used in biosynthetic processes (Mu and Hoy, 2004).

MCFAs have been used for years to satisfy the nutritional needs of patients with lipid malabsorption such as Chron's disease, cystic fibrosis, colitis and premature birth (Akoh et al., 2002). However, MCFAs do not satisfy the body's essential fatty acid requirement, so they cannot be used as a lipid source alone (Nunes et al., 2011). For this reason, MLM-type SLs designed as one TAG molecule represent both MCFAs and LCFAs which permit more controlled release of fatty acids into the bloodstream (Osborn and Akoh, 2002). Studies revealed that MLM-type emulsions are the safest and most effective way of energy delivery for patients who need long-term parenteral nutrition (Rubin et al., 2000; Matulka, Noguchi and Nosaka, 2006). The enzymatic synthesis of MLMtype SLs has gained importance in recent years. The enzymatic production of MLM-type SLs has been studied using different substrate sources. In the study by Hita et al. (2009), MLM-type SL with caprylic acid at the $s n-1,3$ positions and docosohexaenoic acid (DHA) at the $s n-2$ position was produced via enzymatic reactions. Researchers concluded that designed SL has the potential of being an important nutritional component for the development of the central nervous system of premature babies. Kim et al. (2010) designed a MLM-type SL consisting of caprylic acid and gamma-linolenic acid (GLA) derived from borage oil by an enzymatic synthesis method for premature babies and for those who have lipid malabsorption such as cystic fibrosis. In another study, corn oil and caprylic acid were the substrates of enzymatic process yielding with MLM-type SL intended for patients with special nutritional requirements (Öztürk, Ustun and Aksoy, 2010). In the study by Nunes et al., (2011), MLM-type SL destined for clinical nutrition was produced via enzymatic reactions between olive oil and capric acid.

SDA is an important fatty acid since it is an intermediate metabolite of the omega- 3 pathway in which alpha-linolenic acid (ALA) is converted to eicosapentaenoic acid (EPA) and docosahexaenoic acid (DHA) and shows similar health effects to EPA and DHA. SDA is more efficiently converted into EPA and DHA when compared to ALA (Whelan, 2009). Oil from the plant source Echium plantagineum L., Boraginaceae, a black currant from the families Primulaceae and Grossulariaceae, have high concentrations of SDA, and also some microbial oils; fish oils, and genetically engineered soybean and canola are the sources of SDA (Whelan, 2009; Surette, 2013). SDA originated from plants has the potential of being a sustainable and vegetarian EPA source since EPA is mainly derived from fish oils. Fish stocks are being depleted day by day due to over fishing activities and the negative effects of climate change. Also, fish oils may have some environmental pollution (dioxins, polychlorated biphenyls, toxic heavy metals such as mercury) as well as an undesired smell and taste (Chávez-Servín et al., 2009). Furthermore, the PUFA content of the oil reaches up to nearly $60 \%$. Thus, due to the high presence of SDA content in Echium oil, it was chosen as one of the substrate oils. Since the aim of the study was to incorporate long-chain fatty acids into the $s n-2$ position of the SLs, Echium oil served to fulfill the desired oil composition and distribution of fatty acids in the newly synthesized TAG structure.

In the literature, there are several studies about enzymatically synthesized SLs with the use of different SDA plant sources as substrate oil. In the study by Kleiner et al., (2012), firstly, low temperature crystallization (LTC) was applied in order to increase SDA content in modified soybean oil from $25 \%$ to $48.72 \%$ (TAG) and $60.78 \%$ (FFA). In the next step, SL with the highest SDA content $(53.46 \pm 1.85 \%$ SDA with $36.37 \pm 3.14 \%$ at $\mathrm{sn}-2$ position) was produced via the acidolysis reaction between the TAG and FFA of LTC catalyzed by Lipozyme ${ }^{\circledR}$ TL IM in solvent free conditions. Ifeduba and Akoh (2014) used genetically modified SDA soybean oil and caprylic acid to produce 
SLs via enzymatic reactions in their study. In an another study, Gökçe et al., (2013) obtained low calorie SL with $64.4 \%$ PUFA content at the $s n-2$ position via the enzymatic acidolysis reaction catalyzed by Lipozyme ${ }^{\circledR}$ RM IM where Echium oil and lauric acid were used as oil sources. Bilgiç et al., (2012) used Echium oil and olive oil as substrates of enzymatic acidolysis reactions catalyzed by Lipozyme ${ }^{\circledR}$ TL IM in order to incorporate SDA into olive oil. As a result of the study, SLs were produced with $4.9 \%$ SDA and $43 \%$ PUFA contents. To sum up, previous studies used SDA rich oil sources or Echium oil to enrich oils in terms of omega-3 and omega-6 PUFAs (Bilgiç and Yeşilçucuk, 2012; Kleiner et al., 2012; Gökçe, Sahin-Yeşilçubuk and Üstün, 2013; Ifeduba and Akoh, 2014). However, no previous study investigated the influence of reaction conditions for obtaining MLM-type SL from Echium oil fatty acids and tricaprylin. Therefore, the aim of this study was the production and optimization of MLM-type SLs containing SDA via enzymatic acidolysis reactions. In order to characterize the products, the fatty acid composition, $s n-2$ positional composition and melting profiles of the SLs were determined.

\section{MATERIALS AND METHODS}

\subsection{Materials}

The Echium oil (E. plantagineum) used in this study was purchased from the Harke Group, $\mathrm{GmbH}$ (Germany). Tricaprylin was purchased from Sigma Chemical Co. (St. Louis, MO). Lipozyme ${ }^{\circledR}$ RM IM commercially immobilized $s n-1,3$ specific lipase from Rhizomucor miehei was donated by Novo Nordisk A/S branch (İstanbul, Turkey). The enzyme activity of Lipozyme ${ }^{\circledR}$ RM IM was 275 UIN/g. TLC plates were purchased from Merck (Whitehouse, NJ). All other reagents and solvents purchased either from Sigma Chemical Co. (St. Louis, MO) or Merck (Whitehouse, NJ) were of analytical or chromatographic grade.

\subsection{Methods}

\subsubsection{Preparation of free fatty acids from Echium oil}

Echium oil was saponified to obtain free fatty acids according to Yüksel and Yeşilçubuk (2012). For the saponification process, $25 \mathrm{~g}$ of Echium oil and $5.75 \mathrm{~g}$ of $\mathrm{KOH}$ were weighed into a flask and $11 \mathrm{~mL}$ of distilled water and $66 \mathrm{~mL}$ of aqueous ethanol $[95 \%(\mathrm{v} / \mathrm{v})]$ were added to the oil. The mixture was heated in a water bath at $60{ }^{\circ} \mathrm{C}$ for 1 hour. After $1 \mathrm{~h}$, the reaction was stopped by adding $60 \mathrm{~mL}$ of distilled water. The unsaponifiable matter was extracted twice into the hexane layer $(100 \mathrm{~mL})$ and they were discarded. Then, the mixture was acidified $(\mathrm{pH}=1.0)$ with $3 \mathrm{~mol} / \mathrm{L}$ of $\mathrm{HCl}$. After acidification, free fatty acids were extracted into $50 \mathrm{~mL}$ of hexane which was further passed through anhydrous sodium sulfate column. Hexane was evaporated at $40{ }^{\circ} \mathrm{C}$ using a rotary evaporator. The free fatty acids were stored at -18 ${ }^{\circ} \mathrm{C}$ for further use.

\subsubsection{Acidolysis reactions}

Acidolysis reactions with different molar ratios of free fatty acids and tricaprylin were performed in screw-capped amber glass bottles (Table 1). Lipozyme $^{\circledR}$ RM IM (10\% weight of total substrates) was added to the reaction medium together with 3 $\mathrm{mL}$ of $n$-hexane. The reaction mixture was placed in an orbital shaker (IKA, KS4000i, Germany) rotating at $200 \mathrm{rpm}$ under different conditions determined by the RSM design generated by Modde 11.0 (Umetrics, Umeå, Sweden). After the enzymatic reactions, the reaction mixture was passed through a glass column packed with anhydrous sodium sulfate as described in Sahin et al., (2005a). All reactions were carried out in duplicate and the results are reported as the average data.

TABLE 1. Experimental design and observed responses for incorporation of SDA $(\mathrm{mol} \%)^{\mathrm{a}, \mathrm{b}}$

\begin{tabular}{lcccc}
\hline $\begin{array}{c}\text { Experiment } \\
\text { No }\end{array}$ & $\mathbf{T}\left({ }^{\circ} \mathbf{C}\right)$ & $\mathbf{t}(\mathbf{h})$ & $\mathbf{S}_{\mathbf{r}}(\mathbf{m o l} / \mathbf{m o l})$ & $\begin{array}{c}\text { SDA incorporation } \\
(\mathbf{m o l} \text { \%) }\end{array}$ \\
\hline 1 & 50 & 6 & 3 & 4.28 \\
2 & 50 & 12 & 3 & 5.07 \\
3 & 60 & 6 & 3 & 3.91 \\
4 & 60 & 12 & 3 & 5.09 \\
5 & 50 & 6 & 6 & 5.46 \\
6 & 50 & 12 & 6 & 6.19 \\
7 & 60 & 6 & 6 & 6.06 \\
8 & 60 & 12 & 6 & 6.13 \\
9 & 55 & 3.95 & 4.5 & 4.50 \\
10 & 55 & 14.05 & 4.5 & 6.21 \\
11 & 46.59 & 9 & 4.5 & 4.80 \\
12 & 63.41 & 9 & 4.5 & 6.18 \\
13 & 55 & 9 & 1.98 & 3.55 \\
14 & 55 & 9 & 7.02 & 7.08 \\
15 & 55 & 9 & 4.5 & 5.65 \\
16 & 55 & 9 & 4.5 & 6.10 \\
17 & 55 & 9 & 4.5 & 5.78 \\
\hline
\end{tabular}

${ }^{\mathrm{a}}$ Mean, $n=2$.

${ }^{\mathrm{b}}$ Abbreviations: $\mathrm{T}$, reaction temperature $\left({ }^{\circ} \mathrm{C}\right)$; $\mathrm{t}$, reaction time (h); Sr: substrate molar ratio (mole of total free fatty acids/mole of tricaprylin). 


\subsubsection{Experimental design for RSM study}

A three-factor, 5-level central composite circumscribed design (CCC) was applied by the use of Modde 11.0 (Umetrics, Umeå, Sweden) software to investigate how the chosen parameters affect the incorporation of SDA during the enzymatic reactions. Reaction temperature $\left(\mathrm{T},{ }^{\circ} \mathrm{C}\right)\left(50-60^{\circ} \mathrm{C}\right)$, reaction time $(\mathrm{t}, \mathrm{h})(6-12 \mathrm{~h})$ and substrate molar ratio $(\mathrm{Sr}$, total free fatty acids/tricaprylin $(3-6 \mathrm{~mol} / \mathrm{mol})$ were the parameters of the response surface methodology (RSM) study. The factor ranges were selected according to the preliminary studies (data not given here) and the literature survey. Table 1 shows the independent variables together with the experimental design of this study. The experiments were carried out randomly and the average of two parallel results for each experimental point is reported as the mol $\%$ of the fatty acids.

\subsubsection{Analysis of reaction products}

The reaction products $(50 \mu \mathrm{L})$ were separated as TAG bands on a silica gel G TLC plate $(20 \mathrm{x}$ $20 \mathrm{~cm}$ ) using a petroleum ether, diethyl ether, and acetic acid $(80: 20: 0.5, \mathrm{v} / \mathrm{v} / \mathrm{v})$ mixture as the solvent system. $0.2 \%$ 2,7-dichlorofluorescein in methanol was sprayed onto the TLC plate to make the TAG bands visible under UV light. Then, the TAG bands were incubated with $3 \mathrm{~mL}$ of $6 \% \mathrm{HCl}$ in methanol and $40 \mu \mathrm{L}$ of $\mathrm{C} 17: 0$ as internal standard $(10 \mathrm{mg} / \mathrm{mL})$ in test tubes and they were placed in an oven at 75 ${ }^{\circ} \mathrm{C}$. After 2 hours, the reaction products were mixed with $2 \mathrm{~mL}$ of $n$-hexane and $1 \mathrm{~mL}$ of $0.1 \mathrm{M} \mathrm{KCl}$ and centrifugated at $1000 \mathrm{rpm}$ for 3 minutes to obtain the upper layer which was then passed through an anhydrous sodium sulfate column. Finally, the fatty acid methyl esters (FAME) obtained were analyzed by gas chromatography to evaluate the fatty acid composition of the substrate oils and reaction products (Jennings and Akoh, 1999).

\subsubsection{Fatty acid composition analysis}

Shimadzu GC 2010 Plus gas-liquid chromatography (GLC) (Milan, Italy) equipped with a flame-ionization detector (FID) and SP-2380 capillary column $(60 \mathrm{~m} \times 0.32 \mathrm{~mm}$ ID $\times 0.20 \mu \mathrm{m}$ film thickness) (Supelco Inc., Bellefonte, PA, USA) was used to evaluate the substrate oils and reaction products for their fatty acid compositions. Both the injector and detector temperatures were held at $250{ }^{\circ} \mathrm{C}$. The oven temperature was initially held at $60{ }^{\circ} \mathrm{C}$ for $1 \mathrm{~min}$, and then programmed to $165^{\circ} \mathrm{C}$ for $30 \mathrm{~min}$ at a rate of $20^{\circ} \mathrm{C} / \mathrm{min}$ (first ramp); to $190{ }^{\circ} \mathrm{C}$ for $35 \mathrm{~min}$ at a rate of $10^{\circ} \mathrm{C} /$ min (second ramp); to $210{ }^{\circ} \mathrm{C}$ for $10 \mathrm{~min}$ at a rate of $20^{\circ} \mathrm{C} / \mathrm{min}$ (third ramp). Hydrogen was used as the carrier gas at a flow rate of $1.02 \mathrm{~mL} / \mathrm{min}$. The sample volume was $1 \mu \mathrm{L}$ and relative amounts of FAME were calculated as mol \% fatty acid (FA) by computer with reference to heptadecanoic acid as the internal standard. The reported results were the average values of duplicate analyses.

\subsection{6. $S n-2$ positional fatty acid analysis}

The TAG bands scrapped off from the TLC plates were incubated with a $1.0 \mathrm{M}$ Tris- $\mathrm{HCl}$ buffer $(2 \mathrm{~mL}), 0.05 \%$ bile salt solution $(0.5 \mathrm{~mL}), 2.2$ $\mathrm{g} / 100 \mathrm{~g}$ calcium chloride solution $(0.2 \mathrm{~mL})$ and pancreatic lipase $(40 \mathrm{mg})$ in the test tubes placed in a water bath at $40{ }^{\circ} \mathrm{C}$ for $3 \mathrm{~min} .6 \mathrm{~mol} / \mathrm{L} \mathrm{HCl}(1$ $\mathrm{mL})$ and diethyl ether $(4 \mathrm{~mL})$ were added and then centrifuged. An anhydrous sodium sulfate column was used to filter the upper phase. Thereafter, a $200 \mu \mathrm{L}$ aliquot was spotted on TLC plates coated with silica gel G, and the TLC plates were placed in the tank and hexane, diethyl ether, and formic acid (60:40:1.6, v/v/v) were used as developing solvents. After the band seperation, 2,7-dichlorofluorescein in methanol $(0.2 \mathrm{~g} / 100 \mathrm{~mL})$ was sprayed onto the TLC plate in order to visualise the 2-monoacylglycerol (2-MAG) band under UV light. For identification, a 2-monoolein standard (Sigma) was used as a marker. The 2-MAG band corresponding to the marker bang was scrapped off into a screw-capped test tube, methylated and analyzed by GLC as previously described (Pina-Rodriguez and Akoh, 2009).

\subsubsection{Scale-up process}

For scale-up synthesis of SLs, the optimum reaction conditions generated by RSM were employed. The levels of tricaprylin and total free fatty acids were increased by approximately 40 times. Also, enzyme and hexane levels were scaled-up to levels which agreed with the increased amount of substrate oils. The reaction mixture containing substrates at a $6 \mathrm{~mol} / \mathrm{mol}$ substrate molar ratio was incubated at $60^{\circ} \mathrm{C}$ and agitated in an orbital shaking air-bath at $200 \mathrm{rpm}$ for 6 hours. In the end, the mixture was passed through anhydrous sodium sulfate column in order to stop the enzymatic reaction.

\subsubsection{Removal of free fatty acids from the reaction mixture}

The reaction products from the scale-up process were purified according to the procedure outlined by (Lee et al., 2004). After the enzymatic interesterification reaction, excess hexane was removed by a rotary evaporator, and $60 \mathrm{~mL}$ of $0.5 \mathrm{~mol} / \mathrm{L}$ $\mathrm{KOH}$ solution prepared with ethanol $(20 \mathrm{~mL} / 100$ $\mathrm{mL}$ ) and $110 \mathrm{~mL}$ hexane were added to the product subsequently transferred to a separatory funnel. The upper layer was collected, mixed with 3-4 
drops of phenolphthalein solution and titrated with $0.5 \mathrm{~mol} / \mathrm{L} \mathrm{KOH}$ solution prepared with ethanol $(20 \mathrm{~mL} / 100 \mathrm{~mL}) .30 \mathrm{~mL}$ of a saturated $\mathrm{NaCl}$ solution were added to the mixture when the color of the mixture turned to pink. Then, the mixture was shaken vigorously and passed through the anhydrous sodium sulfate column. The collected hexane phase was removed by rotary evaporator and kept at $-18^{\circ} \mathrm{C}$ until use.

\subsubsection{Melting profile determination}

The melting profiles of tricaprylin, Echium oil and the SL product of the scale-up process were determined by differential scanning calorimetry (DSC) Q10 model (TA Instruments, New Castle, DA) according to the AOCS Official Method $\mathrm{Cj}$ 1-94 (1989).

\subsection{Statistical analysis}

The regression analysis, statistical significance, analysis of variance (ANOVA), and response surface applications were carried out using Modde 11.0 (Umetrics, Umeå, Sweden) software. Second-order coefficients were generated by regression analysis. The goodness of fit of the model was evaluated by the coefficient of determination $\left(R^{2}\right)$ and ANOVA data.

A second-order polynomial model was used to fit the data obtained from the experimental design as shown in equation 1 :

$$
Y=\beta_{0}+\sum_{i=1}^{3} \beta_{i} X_{i}+\sum_{i=1}^{3} \beta_{i i} X_{i}^{2}+\sum_{i=1}^{2} \sum_{j=i+1}^{3} \beta_{i j} X_{i} X_{j}
$$

where $Y$ is the response (incorporation of SDA at $s n-1,2,3$ positions), $\beta_{0}$ is the intercept; $\beta_{i}$ is the linear term (first-order model); $\beta_{i i}$ is the quadratic term (second-order model), $\beta_{i j}$ is the interaction regression coefficient, and $X_{i}$ and $X_{j}$ are the independent variables.

\section{RESULTS AND DISCUSSION}

\subsection{Fatty acid profile of the substrate oils}

The fatty acid profile of the substrate oils (tricaprylin and Echium oil) was determined by GLCFID. The samples were analyzed in duplicate and average results were calculated. According to the results, tricaprylin consisted of $99.5 \%$ caprylic acid. In addition, Echium oil fatty acids contained predominantly $\alpha$-linolenic acid $(31.7 \%)$, oleic acid $(14.5 \%)$, linoleic acid (14.1\%), stearidonic acid $(13.7 \%)$ and $\gamma$-linolenic acid $(10.7 \%)$. The fatty acid profile of Echium oil fatty acids was found to be close to the Echium oil fatty acid composition
(Guil-Guerrero et al., 2000; Özcan, 2008; Bilgiç and Yeşilçubuk, 2012).

\subsection{Model fitting for the optimization study}

The present study aimed at the production of MLM-type SLs containing stearidonic acid at the $s n-2$ position between tricaprylin and the free fatty acids of Echium oil by enzymatic acidolysis reactions. An experimental design with three-factor and five-level CCC was applied in order to optimize the reaction conditions. Table 1 shows each design point and observed responses in terms of SDA incorporation at the $s n-1,2,3$ positions (mol \%). Regression coefficients $(\beta)$ and significance $(P)$ values are given in Table 2.

As can be seen from Table 2, the first-order parameters such as time (t) and substrate molar ratio $(\mathrm{Sr})$ were significant and they both had positive effects on the incorporation of SDA. Since the other terms such as temperature, quadratic terms and interaction terms were not found to be significant, they are not presented in Table 2. Therefore, the model equation including the significant terms for SDA incorporation at the $s n-1,2,3$ positions can be written as:

$$
\begin{aligned}
\text { SDA incorporation }(\mathrm{mol} \%) & =5.85+0.41 \mathrm{t} \\
& +0.0 .84 \mathrm{Sr}(2)
\end{aligned}
$$

Fitness of the model was evaluated by analysis of variance, and the results are given in Table 3 . According to the ANOVA analysis presented in Table 3 , since $F_{\text {model }}(8.07)$ is very high compared to the $F_{9,7}$ value (3.69) $(\alpha=0.05)$, the obtained model is regarded as suitable for prediction (Sahin et al., 2005a; Sahin et al., 2005b; Yüksel and Yeşilçubuk, 2012). In addition, model error is used to determine whether the model is fit to the results of the experiment. Since the $p$ value of the model error for SDA incorporation at the $s n-1,2,3$ positions was 0.195 , there was no significant $(p>0.05)$ lack of fit in the model (Rao et al., 2002; Lumor and Akoh; 2005; Sahin et al., 2005a; Chopra et al., 2011).

The coefficient of determination $\left(\mathrm{R}^{2}\right)$ for SDA incorporation at the $s n-1,2,3$ positions was found to be 0.91 . Also, the relationship between the observed and predicted values from the model is given in

TABLE 2. Regression coefficients $(\beta)$ and significance levels $\left(P\right.$-Values) for incorporation of $\mathrm{SDA}^{\mathrm{a}}$

\begin{tabular}{lcc}
\hline Variables & Coefficients $(\boldsymbol{\beta})$ & $\boldsymbol{P}_{\text {-value }}$ \\
\hline Constant & 5.85 & $<0.0001$ \\
$\mathrm{t}$ & 0.41 & 0.0092 \\
$\mathrm{Sr}$ & 0.84 & 0.002 \\
\hline
\end{tabular}

${ }^{\mathrm{a}} P$ value, level of significance. See Table 1 for other abbreviations. 
TABLE 3. ANOVA table for SDA incorporation ${ }^{\mathrm{a}}$

\begin{tabular}{lccccc}
\hline & \multicolumn{5}{c}{ SDA Incorporation } \\
\cline { 2 - 6 } & DF & SS & MS & $\boldsymbol{F}$ value & $\boldsymbol{P}$-value \\
\hline Total & 17 & 512.96 & 30.17 & & \\
Constant & 1 & 498.32 & 498.32 & & \\
Total corrected & 16 & 14.65 & 0.92 & & \\
Regression & 9 & 13.36 & 1.48 & 8.07 & 0.006 \\
Residual & 7 & 1.29 & 0.18 & & \\
$\begin{array}{l}\text { Lack of fit } \\
\text { (model error) }\end{array}$ & 5 & 1.18 & 0.24 & 4.40 & 0.195 \\
$\begin{array}{l}\text { Pure error } \\
\text { (replicate error) }\end{array}$ & 2 & 0.11 & 0.05 & & \\
\hline
\end{tabular}

${ }^{a}$ Abbreviations: DF, Degree of freedom; SS, Sum of squares; MS, Mean squares.

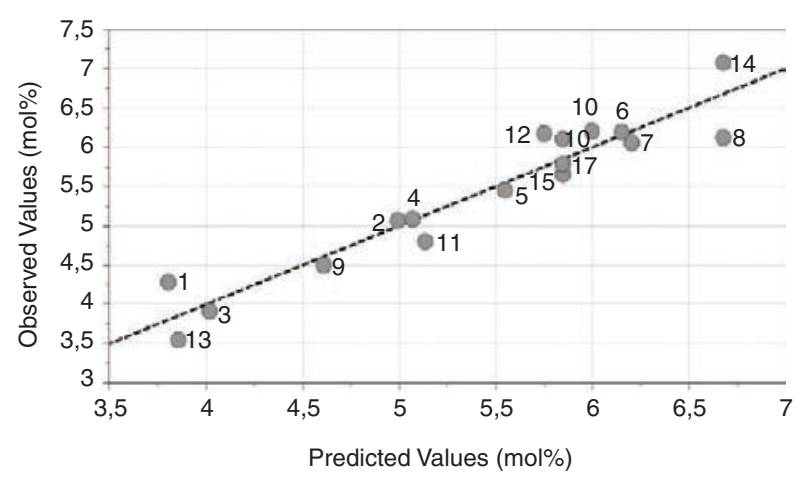

FIgURE 1. The observed vs. predicted plot of SDA incorporation.

Figure 1. According to the graph in Figure 1, the observed vs. predicted plot of SDA showed a linear distribution. This also means that the model generally represents the real relationship between the reaction parameters and the response (Yang et al., 2003).

\subsection{Optimization study}

Response surface methodology was used to evaluate and to predict/optimize the relationship between the reaction parameters and the response. The contour plots obtained from the interaction of temperature, time and substrate molar ratio on the enzymatic incorporation of SDA into tricaprylin are given in Figures 2a, 2b and 2c. While drawing the contour plots, the third variables were kept at medium values.

As can be seen from Figure 2a, SDA incorporation at the $s n-1,2,3$ positions increases with the increase in both time and substrate molar ratio within the observed experimental ranges (Temperature: $60{ }^{\circ} \mathrm{C}$ ).

The effects of substrate molar ratio and temperature on the incorporation of SDA at $s n-1,2,3$ positions are shown in Figure 2b. It can be seen that SDA incorporation increases with increasing substrate molar ratio almost independently from temperature within the observed experimental ranges (Time: 9 h).

The effects of time and temperature on the incorporation of SDA at the $s n-1,2,3$ positions are shown in Figure 2c. According to this figure, SDA incorporation increases with the increase in time within the observed experimental ranges (Substrate molar ratio: $6 \mathrm{~mol} / \mathrm{mol}$ ).

In this work, it was aimed to maximize the SDA incorporation at the $s n-1,2,3$ positions, thus according to the optimizer function of Modde 11.0 , the optimal conditions for the maximum incorporation of SDA $(6.8 \mathrm{~mol} \%)$ were found to be $59.9^{\circ} \mathrm{C}, 10.7$ hours and $6.6 \mathrm{~mol} / \mathrm{mol}$ for temperature, time and substrate molar ratio, respectively. In order to reduce the cost of the enzymatic process, lower substrate molar ratio and a shorter reaction time were selected as optimal conditions for SDA incorporation which were $60{ }^{\circ} \mathrm{C}$ reaction temperature, $6 \mathrm{~h}$ reaction time and $6 \mathrm{~mol} / \mathrm{mol}$ substrate molar ratio. At these reaction conditions, 6.1\% SDA incorporation was predicted from the generated model.

\subsection{Model verification and scale-up production at optimal reaction conditions}

The optimal conditions for SDA incorporation at the $s n-1,2,3$ positions were determined to be $60{ }^{\circ} \mathrm{C}$, $6 \mathrm{~h}$ and $6 \mathrm{~mol} / \mathrm{mol}$ substrate molar ratio and SDA incorportion was predicted as $6.1 \%$ under these conditions. In order to confirm the prediction power of the model, the enzymatic reactions were performed under these conditions at small scale. Moreover, the scale-up process was also carried out at these optimum conditions. The results of both small-scale and scale-up processes are given in Table 4. As can be seen in Table 4, the experimental incorporation values for SDA obtained from both small-scale $(6.1 \%)$ and scale-up $(6.6 \%)$ production were satisfactorily close to each other and to the predicted value $(6.1 \%)$ from the generated model. The Sn-2 position of SLs were mostly $(78-79 \%)$ occupied by long-chain fatty acids including palmitic, stearic, oleic, $\alpha$-linolenic and stearidonic acids. In addition to this, the yield of the reaction product after the removal of FFAs was $20.5 \%$.

\subsection{Melting behavior of substrate oils and SL}

The melting behavior of the substrate oils (tricaprylin and Echium oil) and the SL obtained in the scale-up production were evaluated by the DSC melting thermograms shown in Figure 3. The main endothermic peaks are consecutively numbered 
(a)

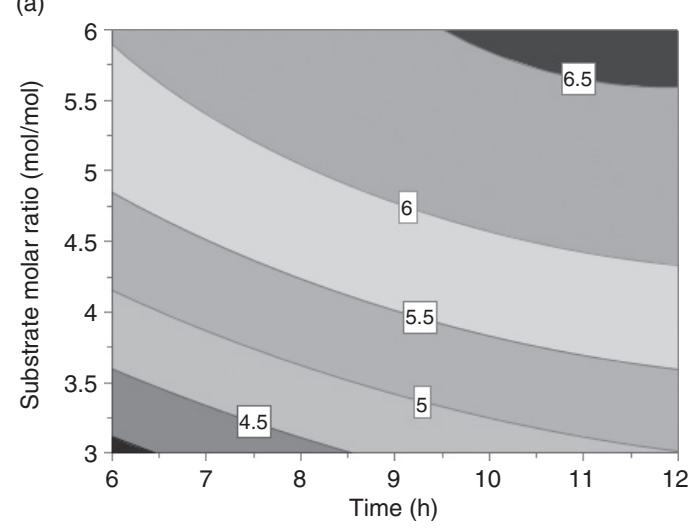

(b)

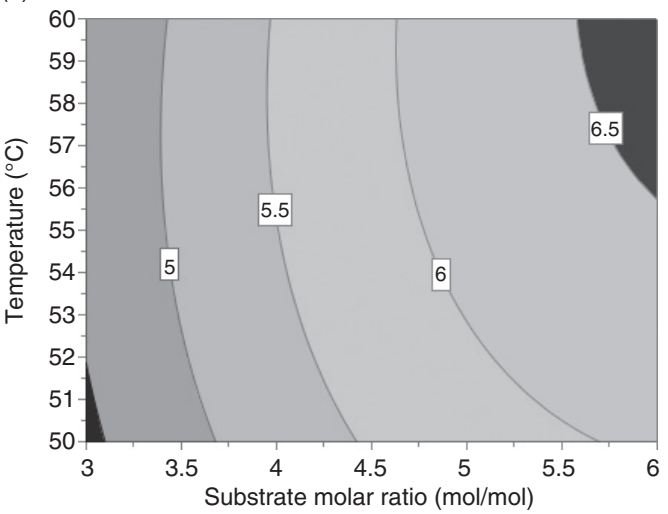

(c)

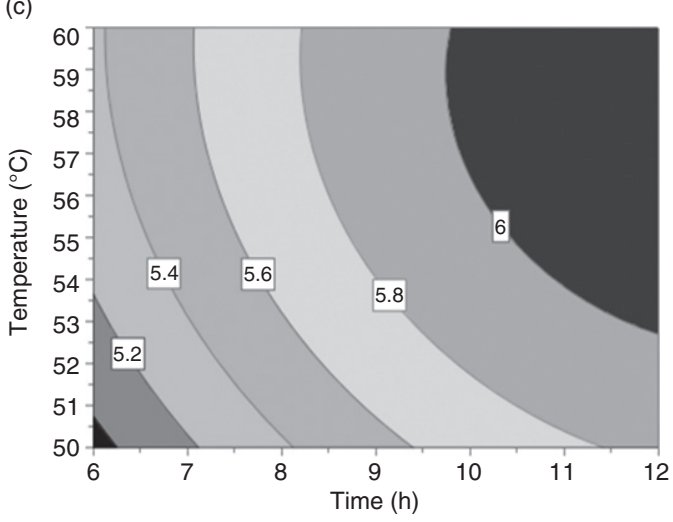

FIGURE 2. Response contour plots between two parameters for SDA incorporation: a substrate molar ratio and time, b temperature and substrate molar ratio, and $\mathbf{c}$ temperature and time.

TABLE 4. Fatty acid composition and $s n-2$ positional distributions of fatty acids ( $\mathrm{mol} \%$ ) of SLs produced under optimal conditions

\begin{tabular}{lcccc}
\hline & \multicolumn{2}{c}{$\begin{array}{c}\text { Small-Scale } \\
\text { Experiments }\end{array}$} & \multicolumn{2}{c}{ Scale-up Process } \\
\cline { 2 - 5 } Fatty Acid & $\boldsymbol{s} \boldsymbol{n - 1 , 2 , 3}$ & $\boldsymbol{s n - 2}$ & $\boldsymbol{s n} \mathbf{- 1 , 2 , 3}$ & $\boldsymbol{s n - 2}$ \\
\hline C8:0 & 50.08 & 21.00 & 53.94 & 21.64 \\
C16:0 & 4.17 & 22.45 & 5.23 & 24.62 \\
C18:0 & 1.78 & 21.67 & 1,94 & 13.92 \\
C18:1n-9 & 7.85 & 20.47 & 7.24 & 17.71 \\
C18:2n-6 & 7.74 & nd $^{\mathrm{a}}$ & 6.31 & $\mathrm{nd}$ \\
C18:3n-6 & 4.60 & $\mathrm{nd}$ & 4.41 & $\mathrm{nd}$ \\
C18:3n-3 & 17.42 & 7.93 & 14.33 & 15.91 \\
C18:4n-3 & 6.06 & 6.48 & 6.61 & 6.20 \\
\hline
\end{tabular}

${ }^{a}$ nd, not detected.

in each thermograph. Figure 3 shows the melting profile of tricaprylin with one sharp peak (peak 3 at $10{ }^{\circ} \mathrm{C}$ ) since it contains saturated fatty acids at about $99.5 \%$. In addition, tricaprylin has another two melting peaks at $-50{ }^{\circ} \mathrm{C}$ and $-15^{\circ} \mathrm{C}$. Echium

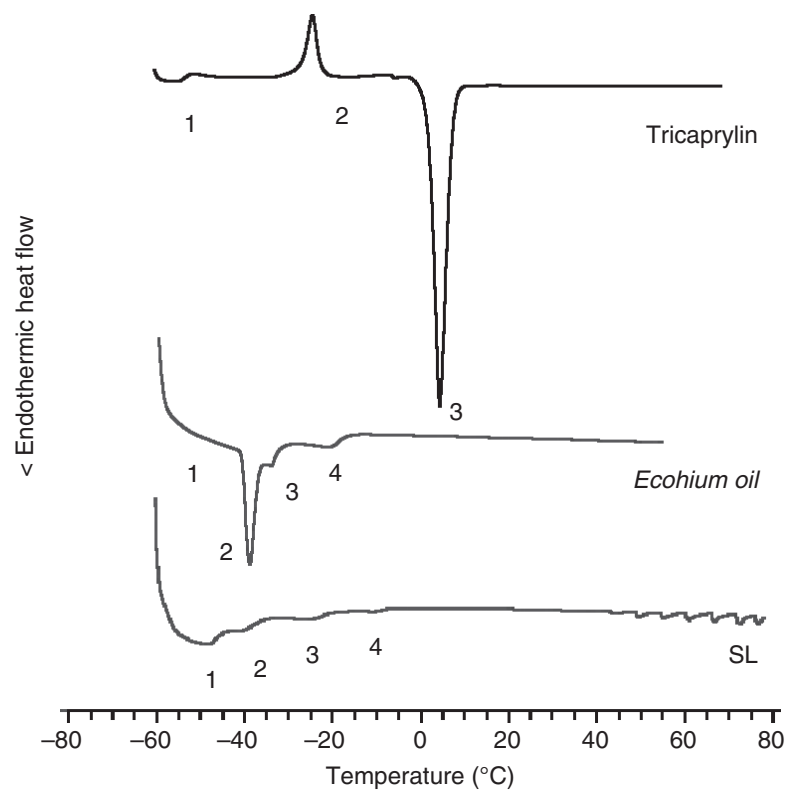

FIGURE 3. DSC melting thermograms of tricaprylin, Echium oil and SL. 
oil has four melting points $\left(-49^{\circ} \mathrm{C},-34{ }^{\circ} \mathrm{C},-27{ }^{\circ} \mathrm{C}\right.$ and $-11^{\circ} \mathrm{C}$, respectively) as can be seen in Figure 3 . If we compare the melting behavior of tricaprylin and Echium oil, Echium oil has a narrower melting point range $\left(-50\right.$ to $\left.-10{ }^{\circ} \mathrm{C}\right)$. Figure 3 also shows the melting thermogram of the SL produced in scaleup process. This thermogram reveals that the incorporation of unsaturated fatty acids into tricaprylin resulted in the presence of new melting points at lower temperatures (peaks 1, 2, 3 and 4 indicated the temperatures $-47^{\circ} \mathrm{C},-37^{\circ} \mathrm{C},-22{ }^{\circ} \mathrm{C}$ and $-6{ }^{\circ} \mathrm{C}$, respectively). Moreover, the characteristic melting peak of tricaprylin (peak 3 of tricaprylin thermogram) disappeared. SL has no characteristic melting peak when compared to the DSC thermograms of tripcaprylin and Echium oil.

\section{CONCLUSIONS}

The MLM-type structured lipid obtained as a result of this study contained SDA as well as other omega-3 fatty acid ALA together with medium chain caprylic acid. We believe that the MLM-type SLs produced within the concept of this study will satisfy the needs of patients with special nutrition requirements as well as consumers who increasingly demand functional foods with health benefits. These SLs can be used for patients with lipid malabsorption, for premature babies, and for hospitalized patients who require more energy, more quickly. Moreover, the construction of novel or designer structured lipid molecules from Echium oil substrates will be promising for food, therapeutic, and nutritional uses in the near future.

\section{REFERENCES}

Akoh CC, Sellappan S, Fomuso LB, Yankah, VV. 2002. Enzymatic synthesis of structured lipids, in Kuo TM, Gardner HW (Eds), Lipid Biotechnology, Marcel Dekker, Inc., New York, pp. 432-460. https://doi. org/10.1201/9780203908198

AOCS Official Method Cj 1-94. 1989. Official methods and recommended practices of the American Oil Chemists' Society, in Firestone D (Ed), 4th edn, American Oil Chemists' Society, Champaign IL.

Bilgiç S, Yeşilçubuk NŞ. 2012. Lipase-Catalyzed Acidolysis of Olive Oil with Echium Oil Stearidonic Acid: Optimization by Response Surface Methodology. J. Am. Oil Chem. Soc. 89, 1971-1980. https://doi.org/10.1007/s11746-012-2097-8

Chávez-Servín JL, Castellote AI, Martín M, Chifré R, LópezSabater MC.2009. Stability during storage of LC-PUFAsupplemented infant formula containing single cell oil or egg yolk, Food Chem. 113, 484-492. https://doi. org/10.1016/j.foodchem.2008.07.082

Chopra R, Rastogi NK, Sambaiah K. 2011. Enrichment of rice bran oil with $\alpha$-linolenic acid by enzymatic acidolysis: Optimization of parameters by response surface methodology. Food Bioproc. Tech. 4, 1153-1163. https://doi. org/10.1007\%2Fs11947-009-0191-1

Gökçe G, Şahin-Yeşilçubuk N, Üstün G. 2013. Enzymatic production of low-calorie structured lipid from Echium seed oil and lauric acid: optimisation by response surface methodology. J. Food Sci. Technol. 48, 1383-1389. https://doi. org/10.1111/ijfs. 12099
Guil-Guerrero JL, Gómez-Mercado F, García-Maroto F, Campra-Madrid P. 2000. Occurrence and characterization of oils rich in $\gamma$-linolenic acid Part I: Echium seeds from Macaronesia. Phytochem. 53, 451-456. https://doi. org/10.1016/S0031-9422(99)00549-X

Hita E., Robles A, Camacho B, González PA, Esteban L, Jiménez MJ, Muñío MM, Molina E. 2009. Production of structured triacylglycerols by acidolysis catalyzed by lipases immobilized in a packed bed reactor. Biochem. Eng. J. 46, 257-264. https://doi.org/10.1016/j.bej.2009.05.015

Ifeduba EA, Akoh CC. 2014. Modification of stearidonic acid soybean oil by 1mmobilized Rhizomucor miehei lipase to incorporate caprylic acid. J. Am. Oil Chem. Soc. 91, 953965. https://doi.org/10.1007/s11746-014-2433-2

Jennings BH, Akoh CC. 1999. Enzymatic modification of triacylglycerols of high eicosapentaenoic and docosahexaenoic acids content to produce structured lipids. J. Am. Oil Chem. Soc. 76, 1133-1137. https://doi.org/10.1007/ s11746-999-0085-4

Kim H-R, Hou CT, Lee K-T, Kim BH, Kim I-H. 2010. Enzymatic synthesis of structured lipids using a novel cold-active lipase from Pichia lynferdii NRRL Y-7723. Food Chem. 122, 846-849. https://doi.org/10.1016/j. foodchem.2010.03.067

Kleiner L, Vázquez L, Akoh CC. 2012. Increasing Stearidonic Acid (SDA) in Modified Soybean Oil by Lipase-Mediated Acidolysis. J. Am. Oil Chem. Soc. 89, 1267-1275. https:// doi.org/10.1007/s11746-012-2022-1

Lee J-H, Shin J-A, Lee J-H, Lee K-T. 2004. Production of lipase-catalyzed structured lipids from safflower oil with conjugated linoleic acid and oxidation studies with rosemary extracts. Food Res. Int. 37, 967-974. https://doi. org/10.1016/j.foodres.2004.06.005

Lumor SE, Akoh CC. 2005. Enzymatic incorporation of stearic acid into a blend of palm olein and palm kernel oil: Optimization by response surface methodology. J. Am. Oil Chem. Soc. 82, 412-426. https://doi.org/10.1007/ s11746-005-1087-0

Matulka RA, Noguchi O, Nosaka N. 2006. Safety evaluation of a medium- and long-chain triacylglycerol oil produced from medium-chain triacylglycerols and edible vegetable oil. Food Chem. Toxicol. 44, 1530-1538. https://doi. org/10.1016/j.fct.2006.04.004

$\mathrm{Mu}$ H, Høy C-E. 2004. The digestion of dietary triacylglycerols. J. Prog. Lipid Res. 43, 105-133. https://doi.org/10.1016/ S0163-7827(03)00050-X

Nunes PA, Pires-Cabral P, Ferreira-Dias S. 2011. Production of olive oil enriched with medium chain fatty acids catalysed by commercial immobilised lipases. Food Chem. 127, 993998. https://doi.org/10.1016/j.foodchem.2011.01.071

Osborn HT, Akoh CC. 2002. Structured lipids- novel fats with medical, nutraceutical, and food applications. Compr. Rev. Food Sci. Food Saf. 3, 110-120. https://doi. org/10.1111/j.1541-4337.2002.tb00010.x

Özcan T. 2008. Analysis of the total oil and fatty acid composition of seeds of some Boraginaceae taxa from Turkey. Plant Syst. Evol. 274, 143-153. https://doi.org/10.1007/ s00606-008-0039-6

Öztürk T, Ustun G, Aksoy HA. 2010. Production of mediumchain triacylglycerols from corn oil: Optimization by response surface methodology. Bioresour. Technol. 101, 7456-7461. https://doi.org/10.1016/j.biortech.2010.04.096

Pina-Rodriguez AM, Akoh CC. 2009. Enrichment of amaranth oil with ethyl palmitate at the sn-2 position by chemical and enzymatic synthesis. J. Agric. Food Chem. 57, 46574662. https://doi.org/10.1021/jf900242g

Rao R, Manohar B, Sambaiah K, Lokesh BR. 2002. Enzymatic acidolysis in hexane to produce n-3 or n-6 FA-enriched structured lipids from coconut oil: Optimization of reactions by response surface methodology. J. Am. Oil Chem. Soc. 79, 885-890. https://doi.org/10.1007/ s11746-002-0574-7

Rubin M, Moser A, Vaserberg N, Greig F, Levy, Spivak H, et al. 2000. Structured triacylglycerol emulsion, containing both medium- and long-chain fatty acids, in long-term home parenteral nutrition: a double-blind randomized cross-over 
study. Nutrition 16, 95-100. https://doi.org/10.1016/ S0899-9007(99)00249-X

Sahin N, Akoh CC, Karaali A. 2005a. Lipase-catalyzed acidolysis of tripalmitin with hazelnut oil fatty acids and stearic acid to produce human milk fat substitutes. J. Agric. Food Chem. 53, 5779-5783. https://doi.org/10.1021/jf050465e

Sahin N, Akoh CC, Karaali A. 2005b. Enzymatic production of human milk fat substitutes containing $\gamma$-linolenic acid: Optimization of reactions by response surface methodology. J. Am. Oil Chem. Soc. 82, 549-557. https://doi. org/10.1007/s11746-005-1108-z

Surette ME. 2013. Dietary omega-3 PUFA and health: Stearidonic acid-containing seed oils as effective and sustainable alternatives to traditional marine oils. Mol.
Nutr. Food Res. 57, 748-759. https://doi.org/10.1002/mnfr. 201200706

Whelan J. 2009. Dietary stearidonic acid is a long chain (n-3) polyunsaturated fatty acid with potential health benefits. J. Nutr. 139, 5-10. https://doi.org/10.3945/jn.108.094268

Yang T, Xu X, He C, Li L. 2003. Lipase-catalyzed modification of lard to produce human milk fat substitutes. Food Chem. 80, 473-481. https://doi.org/10.1016/S0308-8146(02) 00315-1

Yüksel A, Yeşilçubuk NŞ. 2012. Enzymatic production of human milk fat analogues containing stearidonic acid and optimization of reactions by response surface methodology. LWT-Food Sci. Technol. 46, 210-216. https://doi. org/10.1016/j.1wt.2011.10.004 